\title{
Does empowerment matter? Perceptions of nursing leaders in Pakistan through qualitative approach
}

\author{
Saleema A. Gulzar, Rozina Karmaliani, Kausar S. Khan, Rubina Barolia, Shirin Rahim, Aneeta Pasha \\ School of Nursing and Midwifery, Aga Khan University, Pakistan
}

Received: June 24, 2016

Accepted: July 31, 2016

Online Published: August 31, 2016

DOI: $10.5430 /$ jha.v5n6p28

URL: http://dx.doi.org/10.5430/jha.v5n6p28

\begin{abstract}
Background: In a patriarchal society like Pakistan, where women are oppressed, women dominating professions like nursing is mostly seen as disempowered and requires considerable struggle to achieve its due recognition and respect.

Aim: This study aims to explore the experiences of empowerment among the nursing leaders of Pakistan.

Methods: This study uses a qualitative descriptive design. Total of twelve Pakistani Nursing leaders were interviewed using semi-structured interview guideline to explore their experiences of empowerment.

Results: The study findings revealed five major categories which include: status of a nurse, nursing profession, power relationships, value-belief system, and leadership and management.

Conclusions: Nurses' empowerment is essential for enhancing the image and status of nursing profession in Pakistan. The study identified various personal and professional factors affecting nurses' empowerment in the country and suggests various strategies, such as access to higher nursing education, development of enhanced nursing leadership competencies and understanding of power and politics of the organization, through which nurses can achieve empowerment.
\end{abstract}

Key Words: Nurses, Leaders, Empowerment, Oppression

\section{INTRODUCTION}

The traditional image of nurses is referred to as caring, compassionate and nurturing. Nurses, on one hand are responsible for the provision of safe and competent care to the individuals, families, and communities while on the other hand nurses perform their role as leaders and managers to ensure smooth running of the health care system. Moreover, nursing as a profession is currently viewed as promising by the society as it offers job security, mobility and a rewarding career path. ${ }^{[1]}$ In spite of all these positive qualities, this profession lacks empowerment which is defined as the freedom and power to control their own surrounding. ${ }^{[2]}$ Empowerment also means giving power and authority to someone to make significant life choices. ${ }^{[3]}$ It requires transformation of structures of sub-ordinance, control over material and intellectual resources while gaining decision making authority and minimizing the gender disparity. ${ }^{[4,5]}$ Empowerment plays a crucial role in bringing up positive changes in any profession and professionals and in society as a whole. The outcome of empowerment, for nursing and nurses is in the form of enhanced job satisfaction, strengthened commitment towards the organization they work in, and enhanced retention, and productivity in achieving the organizational goals. $^{[6-8]}$ For society, empowered professionals may become the source of motivation for others, through strong networking, community mobilization and collaboration. ${ }^{[9]}$

\footnotetext{
${ }^{*}$ Correspondence: Saleema A. Gulzar, Asst. Prof.; Email: saleema.gulzar@aku.edu; Address: School of Nursing and Midwifery, Aga Khan University, Pakistan.
} 
This is true for nursing and nurse leaders as is for other professions and professionals. But it is a sad reality, particularly in developing world where generally nurses are counted as an oppressed group in their practice settings, and are governed by other people in an unfair and cruel way with least opportunities of freedom and self-control. The lack of nurses' empowerment is very evident within the nurses working in the various health settings in Pakistan in the form of lack of confidence and low self-esteem. ${ }^{[10]}$ The reason for this lack of empowerment is the historical and social disapproval of the image of nursing and nursing leaders particularly in the third world countries. ${ }^{[1-14]}$ As a result, the image of the nursing profession in developing countries is at stake, and the new generation does not choose the profession as a priority. Crossing the obstacles regarding empowerment and gaining control over oppression is highly recommended for todays' nurses. There arise an urgent need for nurses to enhance the status of the profession and prove themselves to be the professionals who are competent enough of becoming empowered leaders and effective decision makers in the field of their practice. Empowerment is never granted and one has to attain it through dedication and commitment. ${ }^{[15]}$ Hence this is important for nurses to work hard towards gaining the empowerment by respecting and valuing their profession and replacing its negative image with pride.

Nursing literature emphasizes the importance of nurses' empowerment for fulfilling their professional responsibilities of empowering individuals and community for their health and well-being. Literature explicitly claims that nurses cannot empower their clients, if they themselves feel powerless. ${ }^{[16,17]}$ Literature also admits that empowerment, is evolutionary and instrumental, and at times requires bold and demanding steps. Despite many challenges, it is possible to be empowered with conscious efforts and when nurtured, it can become a part of the culture. ${ }^{[3]}$ In the last two decades, this has been proved by few of the nursing institutions that have achieved several milestones for the nursing to combat low social image and status of nurses and nursing profession in Pakistan. ${ }^{[10]}$ There still exists a gap in attaining empowerment and influence of nursing leaders to the extent that they can bring substantial changes at institutional and policy level to improve individual care and working conditions of nurses.

Based on researcher's assumption, nurses' empowerment is an essential element contributing as a positive influence on the nursing profession. This study was commenced to explore experiences of empowerment among nursing leaders of Pakistan.

The purpose of this study is to explore the key concepts of empowerment among nursing leaders in Pakistan which may

Published by Sciedu Press guide current and future nursing leaders to develop strategies to enhance their empowerment within the country.

The following research questions guided the study:

(1) How can the nursing leaders in Pakistan, if become empowered, influence the profession of nursing?

(2) What are the key concepts of empowerment from the perspective of Pakistani nursing leaders?

\section{METHOD}

\subsection{Study design}

A qualitative descriptive approach was used to unfold the phenomena of interest.

\subsection{Sampling and sample size}

A sample of twelve female nursing leaders, working in the administrative capacities of either the nursing service or nursing education sectors of Pakistan was considered. The nurses fulfilling the inclusive criteria were selected from all provinces of Pakistan through purposive sampling method.

The inclusive criteria for this study were that participant nurses must have work experience of not less than 10 years. They can speak Urdu or English, and are willing to voluntarily participate in the study.

All participants were registered nurses working in various nursing organizations with the experience ranging from 1041 years. Their professional academic qualification varied from Ph.D. (2), MSc Nursing (3), BSc Nursing (3), Diploma in Teaching and Administration (3), and Diploma in nursing (1). Sampling and data collection sought the optimum range of variation in categories, until the saturation point. Table 1 describes the demographic data of the study participants.

\subsection{Data collection}

Data were collected using the semi-structured interview guide. The duration of each interview was between 45-60 minutes. Each interview was audio-taped, after obtaining written consent from each participant. The audio taped interviews were transcribed and translated from Urdu to English by the researcher.

\subsection{Data analysis}

The data were initially analyzed by the primary author and later by three of the authors using method of content analysis. ${ }^{[18]}$ The author read and reread the transcripts multiple times. Transcripts were then coded using the open coding to obtain complete data coverage, compared codes with the data and formed categories. Central categories, themes and their relationships were then extracted. As themes emerged, the participants were contacted via phone to either clarify, validate or to obtain further information form the participants. 


\subsection{Ethical consideration}

Permission to conduct the study was sought from the Ethical Review Committee of the Aga Khan University. Informed written consent was obtained at the time of individual initial interviews. Participants were informed about the aim and purpose of the study. Participation in this study was voluntary, and they had the choice to withdraw from the study at any time. Every effort was made to protect the human rights of the participants in the study.

\subsection{Trustworthiness}

Rigor was maintained through credibility, dependability, conformity and transferability. To ensure rigor, researchers read the transcripts multiple times. From the analysis, new categories and themes emerged, and were either added or removed from the data analysis. The researcher continued to interview participants until no new categories were discovered.

\section{RESULTS}

The study findings revealed five key themes in relation to the empowerment of nursing leaders in Pakistan which include: status of a nurse, nursing profession, power relationships, value-belief system, and leadership and management (see Figure 1).

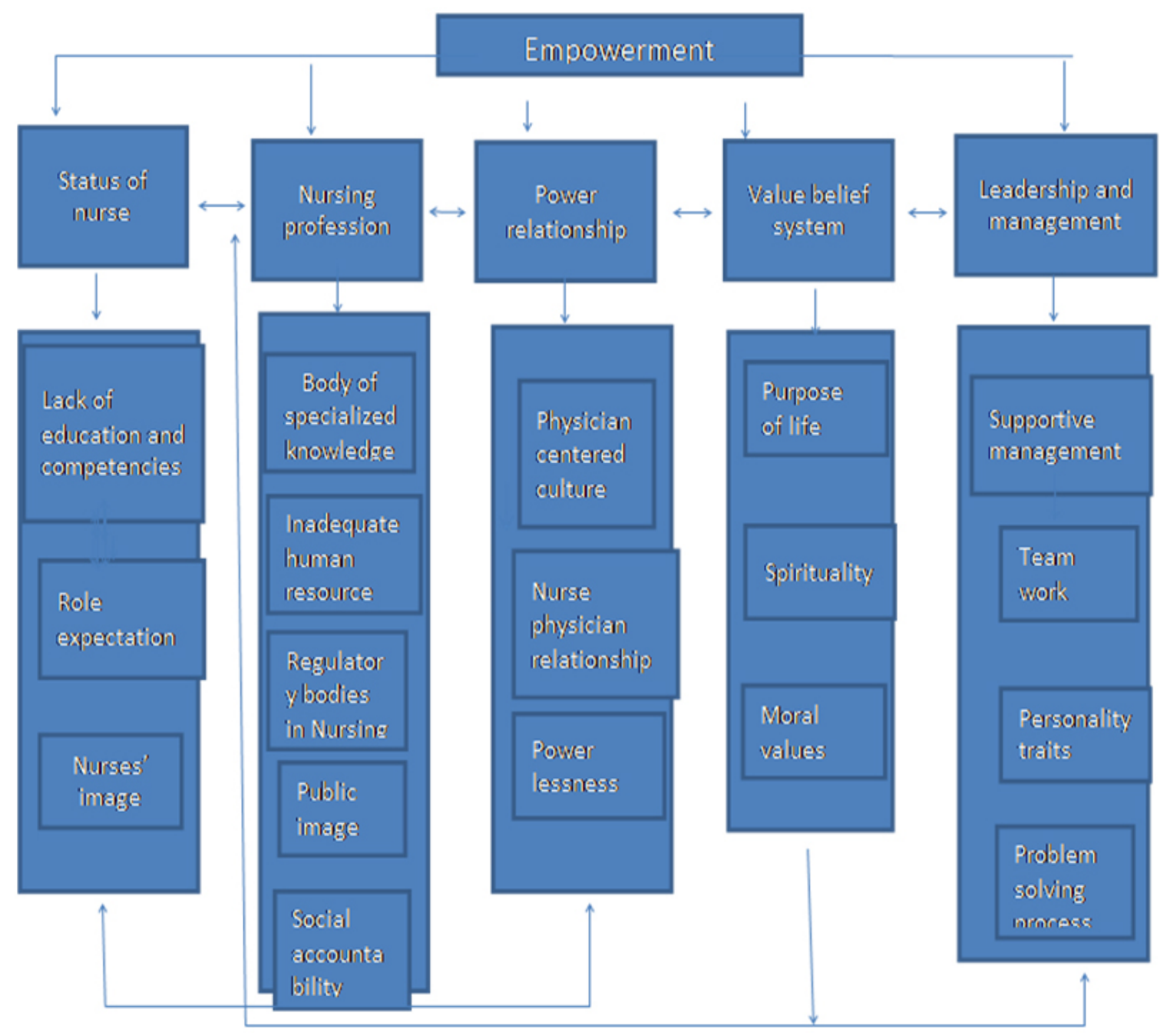

Figure 1. Study findings

This paper focuses on three themes namely power: relationships, value-belief system, and leadership and management. The First two themes of the study including the status of a nurse and nursing profession are being published earlier in a journal relevant to nursing education. ${ }^{[10]}$

\subsection{Power rrelationship}

The data strongly suggests that nursing leaders in Pakistan do not perceive themselves as fully empowered and almost all the nursing leaders shared that they had only limited power. The study participants strongly felt an imbalance in power re- 
lationships within the profession due to the strong influence of the medical model and physicians within the profession.

Subsequent categories within the theme are seen as sub- themes which are interrelated and include: the power of decision making, an influence of medical profession and powerlessness. These are shown in Figure 2.

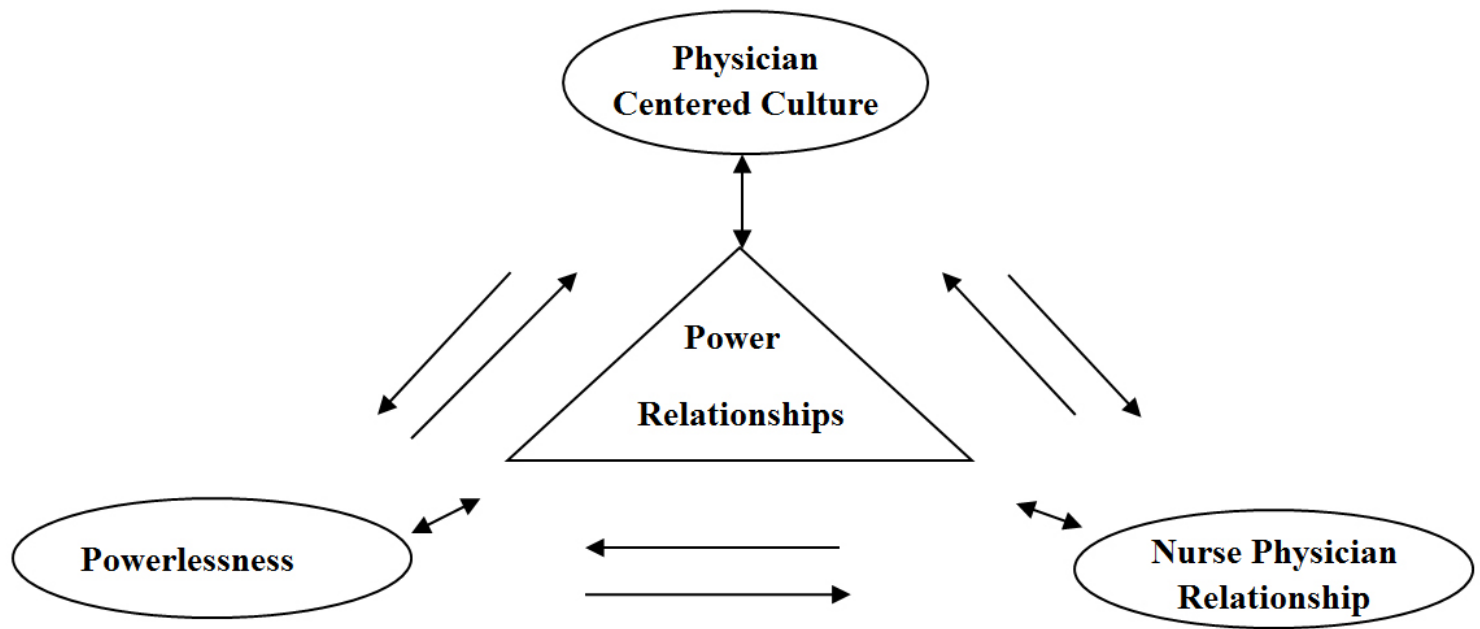

Figure 2. Power relationships

\subsubsection{Physician centered culture}

Participants shared an example of physician-centered culture and power in the local context where inaccuracies made by the physicians are rarely pointed out, as compared to nurses. The errors made by nurses are greatly emphasized and used as a source to blame nurses as inefficient and negligent professionals. Participants also acknowledged the fact that nurses in Pakistan are not considered educated and skillful enough to become powerful leaders, rather they are considered the powerless followers of physicians. This uneven distribution of power which nurses suffer in Pakistan is well shared by one of the study participants who stated:

"When I sit with the physician group, I feel that I am not empowered enough, like my saying is not valued by the president or by the director general, because the physician has more power. Even the chair of the department has more power than me." (ID 002)

\subsubsection{Nurse physician relationship}

The study participants believed that within hospital organizational culture, collegial relationship between nurses and physicians hardly exist; rather nurses are expected to follow or obey physicians hence physicians always view nurses as comparatively inferior to themselves. The system being physician centered does not allow nurses to share the same status and power as of physician. This power imbalance and nurses' continued dependency on physicians create further feelings of powerlessness within nurse leaders. This eventually diminishes nurses' empowerment for decision-

Published by Sciedu Press making and of influencing policy makers for bringing effective change to transform nursing profession and the health care system within the country.

A participant shared a conflict situation with a doctor who blamed her for not following the doctors' instructions. The doctor wanted the nurse to leave the critical patient and help her in turning a patient so that she can examine the patient. Following conversation is reflective of nurse-physician relationship:

"When I refused the doctor that I am not available because I was taking care of critical patients, the doctor asked me to leave the ward, I said to her that I will prioritize my work and will help you when I am done with the patient, but she kept on arguing for long." (ID 001)

Another participant articulated her views in this manner:

“Doctors feel that nurses are under their thumb.” (ID 004)

Participant also verbalized that if physician makes any kind of mistakes they were ignored on the other hand, if nurses make even minor mistakes, they are penalized and face consequences.

For example, a participant elaborated:

"In the joint staffing meetings, I feel so powerless for not being able to defend nurses on simple mistakes. This is because physicians including medical director are not supportive. I have repeatedly noticed that physicians mistakes are never brought to such meetings, and nurses and other paramedical 
staffs' mistakes are highlighted, for example, once a nursing assistant took the biscuit from the patient tray, was highlighted in the meeting and a doctor who ordered the wrong dosage was ignored." (ID 002)

Thus, it can be said that nurses are suppressed because of the strong influence of medical profession. That is one of the major reason which hindering nurses to become empowered.

\subsubsection{Powerlessness}

The concept of powerlessness was explicitly expressed by the participants due to which they have to go to multiple hierarchies for a request to be accepted. The powerlessness in decision making make nurses feel frustrated, helpless, and being hurt. One of the nurse leaders mentioned the situation as follows:

"There were 45 schools of nursing in Punjab. They were under the control of the Director-General nursing but the moment the district government were established, all the schools were given Executive Director Office (EDO). Then my position becomes very awkward. When my instructors or students are in trouble I can't do anything for them. Directly I can't tell them what to do this or do that or I can't help the students over there. I can't transfer the Nursing Instructor, there I am helpless." (ID 004)

Furthermore, participants also stated that there exist various understandings of "being powerful", and "utilization of power" at the nurses' individual levels. Some nursing leaders perceive decision-making authority to be the essential requirement for empowerment and they expressed that they have decision-making power regarding day to day operational issues; however for policy making decisions that require change, they felt to be powerless because of nonfavored organizational processes and hierarchal structures. As one of the leader shared:

"I have some percentage of power... full power is with the Director-General (DG), until and unless we don't have power, we cannot achieve anything." (ID 005)

Whereas in reality, most of the nursing leaders did not have decision making and they are confined only with suggestive authority in their practice setting, which for them is not sufficient condition for being empowered.

A participant shared her feeling and said:

"We were empowered to some extent but the medical and the nursing superintendent positions are not equivalent. Most of the time, the medical superintendent decides for the nursing related matters and the policies; whereas the nursing superintendent only has suggestive authority.” (ID 009)

Despite nurses' hard work and full dedication toward their 32 profession they face instances of having limited power or not having any power for even day to day administrative work. This powerlessness makes their journey towards empowerment more difficult and challenging. Nevertheless the nursing leaders verbalized some constructive derives, which not only assisted them to cope with the challenges of powerlessness successfully, but also made them confident enough to move further up on the road to empowerment. These include "value-believe system" and "leadership and management". These categories are mention below.

\subsection{Value-belief system}

According to the participants, a value-belief system with key values like spirituality and morality and an innate sense of responsibility is highly connected with the concept of "empowerment". The three subthemes related to value belief system included the purpose of life moral values and spirituality which are shown in Figure 3.

\subsubsection{Purpose of life}

Participants shared that empowerment is highly influenced by the individual's philosophy and purpose of life and divine calling which inspires nurses to perform their jobs ethically. It was revealed from the data that the nursing leaders' "purpose of life" continued towards their commitment to the nursing profession. This also proved to be a stepping stone for serving the nursing profession with sincerity and integrity. One participant shared:

"I think in our belief, we are born once only, and everything will be finished, so whatever the responsibilities almighty God or my profession has given should be the purpose of your life, therefore, we should do it honestly and ethically." (ID 004)

\subsubsection{Moral values}

Moral values play a critical role in nurses' empowerment by allowing nurses to become impartial, transparent, and selfless and a fair leader. Acknowledging the role of morality within empowerment, one of the participants said:

"But once empowered you have to be seen as fair, and not taking sides, and transparent that just because you are my friend I will make you my leader, this should not be so. You should be transparent, impartial, fair, self-actualized and hard working so you have to be in a role modeling effect for others. ....." (ID 008)

In addition, one of the other participants highlighted:

"Many a times, we have to be somewhat selfless and should not think for ourselves only. Rather we should show our willingness to empower others by giving time to co-workers, listening to them attentively and helping them achieving their goals." (ID 010) 


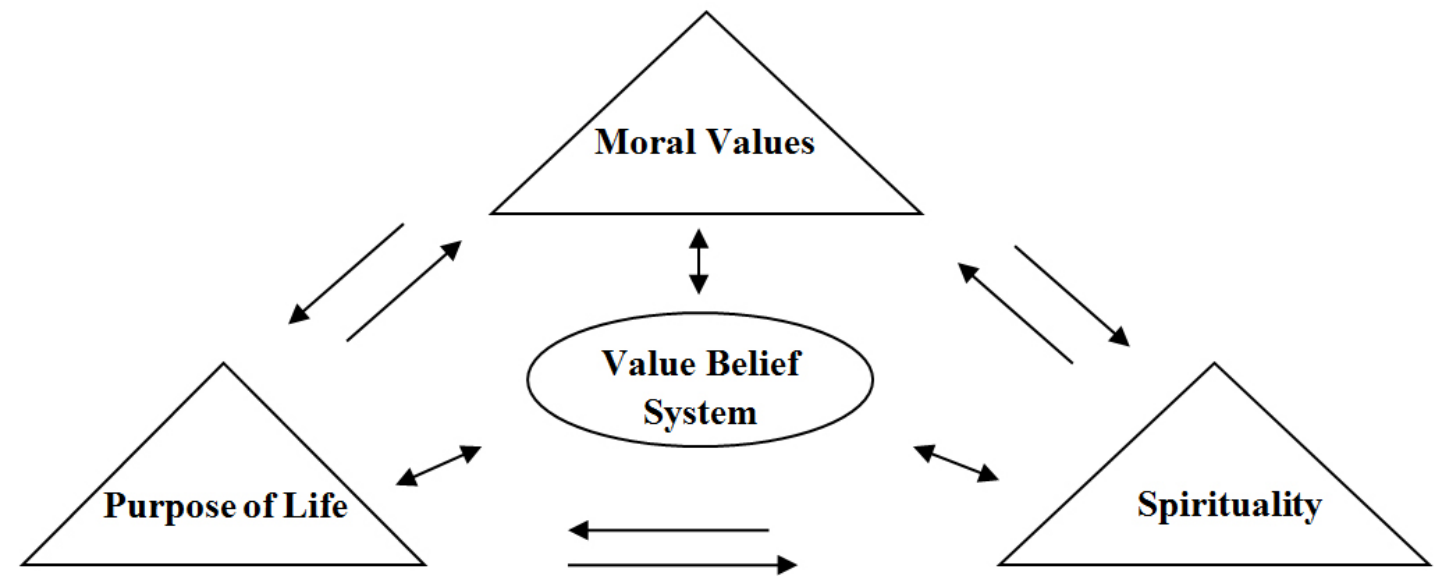

Figure 3. Value-belief system

\subsubsection{Spirituality}

Data from the participants also demonstrated that faith and spirituality are important components that provide them positive energy to perform their job. The concept of "spirituality" instilled in them a confidence that they will be able to achieve their targets and a hope that positive changes will occur. Hence, this served as positive stimulant for most of the nursing leaders. One of the nursing leaders said:

"When I leave home for work, I always recite tasbeeh (prayers), on the way, until I reach office, I only think of
Allah and he gives me the strength and empowerment that I need." (ID 012)

\subsection{Leadership and management}

The concept of leadership and management is quite a broad concept. Data revealed that this concept acted as a constructive drive which has helped nursing leaders to become empowered. The sub categories that emerged from this concept are: mentorship, supportive management, team work, personality traits, and problem solving process. This is shown in Figure 4.

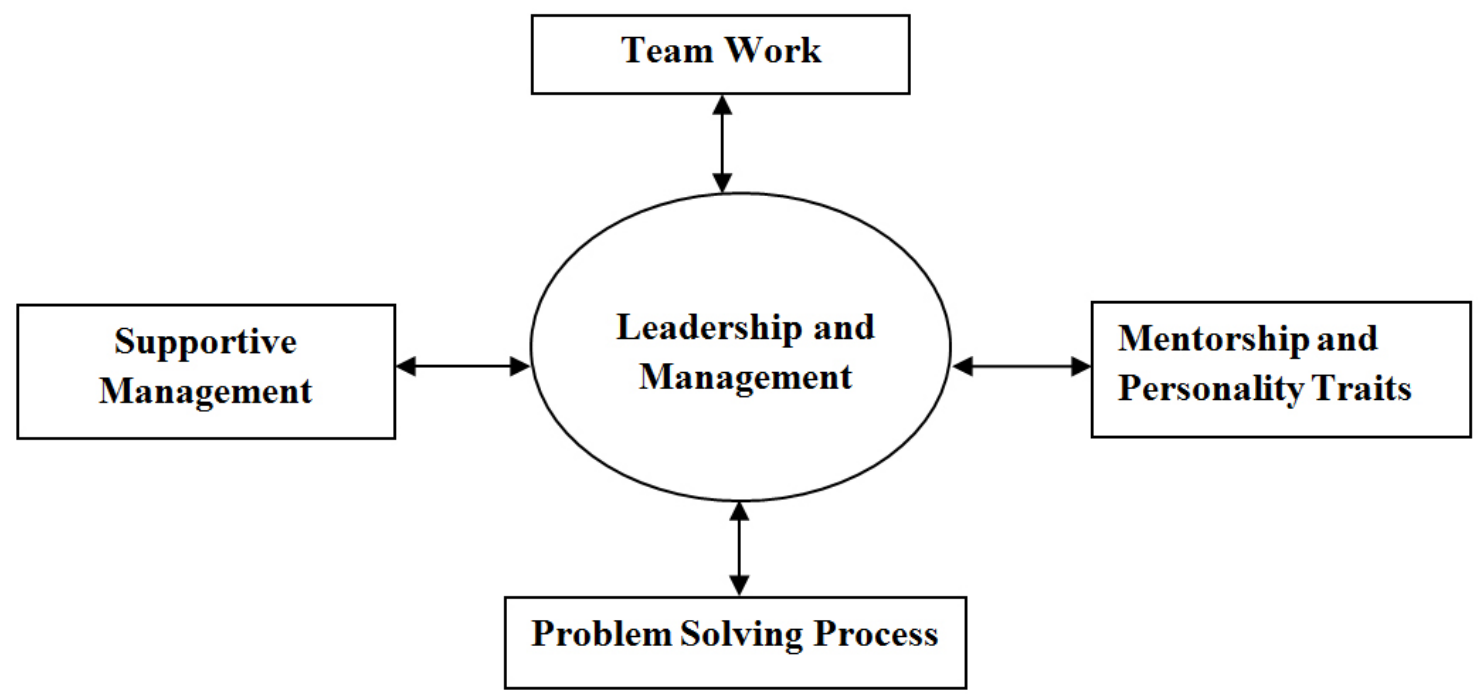

Figure 4. Leadership and management

\subsubsection{Mentorship and personality traits}

Under this sub-theme, the study participants provided key leadership and management roles of an empowered leader and the most important of which is mentorship. Participants claimed that empowered leaders must be good mentors creating a trusting mentorship relationship with fellow nurses.
The leaders must help their mentees in their professional development by giving them responsibilities and guiding them to fulfill these responsibilities efficiently. The study participants agreed that the sense of trust and responsibility that is generated during a mentoring relationship is an important tool for nurses' empowerment. As stated by one participant: 
"Delegate work to people, give them the responsibility and accountability, give them mentorship and support for that, in this way you are giving them work to succeed and not giving them work to fail. This is very important and is seen as a positive tool to empowerment." (ID 008)

Apart from mentorship, participants also shared other important roles of nurse leader which enhance nurses' empowerment include effective problem solving, efficient team work and support management.

Moreover, participants also shared that, there are certain personality traits which are crucial for the empowerment among nurses in Pakistan. The personality traits that had a major influence were: critical thinking, assertiveness, proactivity, flexibility, courage, optimism, and motivation. Participants stressed upon the importance of effective nursing leadership and management to help nurses in releasing them from their "oppressed" state and equipping them with qualities that are significant for empowered leaders.

One of the participants shared:

"Give people space to learn out of their own mistakes. Be there for them, encourage and guide them... trust them and give them some room to improve by providing enabling environment. We have to respect people and accept them with their strengths and weakness, because no one is perfect on the face of this earth.” (ID 010)

\subsubsection{Team work and supportive management}

The participants gave credit to team work, for all the success that they had achieved in their professional life. Participants felt that team work has a great effect in performing their roles and achieving their goals.

As one of the participant said:

“... Single person cannot do anything. We have to decentralize the power and all the team has to work for this. ... and I think organizations cannot cope up with the work if it is done by one person, we have to work as a team." (ID 004)

The role of a supportive management is another important concept that is related to team work is also apparent from the participant's interviews while they are describing empowerment in nursing. The nursing leaders recognized that support and confidence of the higher management could become a source of empowerment for them, as one of the participant said:

"Being administrator of the hospital I found my head nurse and mangers to be very supportive and were willingly reporting to me although I was less qualified from them but they always supported me and respected all my administrated decisions.” (ID 010)

\subsubsection{Problem solving process}

One of the important concepts that have reported by the participants is the problem solving process. As one of the nursing leaders said:

"There were several situations when we wanted to do some work but we couldnot. But then we were given some time, we did analysis, and after doing that we changed our style. Once, we changed the style then we have changed the strategies. Then we proposed some operational plan about how to handle a particular matter." (ID 006)

Excerpts from the data show that the participants stressed on the importance of the concept of leadership and management, which is one of the necessary factors to release from oppression and equip them with qualities that are indeed significant for empowered leaders. The nurses could use these as constructive derives to attain empowerment in Pakistan.

\section{Discussion}

The participants of this study described that empowerment constitutes a raised status, equitable power relations, strong value-belief systems and effective leadership and management.

The key category identified, in the light of power relationships, was the influence of medical professionals. Participants expressed that dominancy of physicians within the health care system is prevalent in Pakistan which makes the organizational culture extremely physician centered. The concern of physician's dominancy in the health care system is well highlighted in literature and is termed as "medical power" and "autonomy" where physicians do not allow nurse leaders to make decisions, most of the time. This is based on their belief that nurses lack necessary knowledge for making sound professional decisions. ${ }^{[19]}$ The culture of physician dominancy affects nurses' empowerment and their retention within the organization. ${ }^{[20]}$ On the contrary, nurses are also being blamed for accepting physician's dominancy and not raising their voice or executing any action against it, and therefore they remain oppressed. ${ }^{[21]}$

In the study almost all nursing leaders felt powerless may be due to societal prejudice of perceiving women as being incapable of demonstrating effective political power. Therefore it is very important that nurses can increase their political power at all levels of politics, from institutional to federal, by using three elements of influence, namely: communication, collectivity, and collegiality. ${ }^{[22-24]}$ There are examples of nurses like Florence Nightingale who used her networking skills with resourceful people in the government to obtain human and material resources, which she needed for wounded soldiers. Another similar example is of Hannah Ropes, who 
in her era had been involved in politics and took a similar course of action. ${ }^{[25]}$ Data from the current study reveals that modern times are no different.

The study also reinforced that one needs to revisit the perceptions on organizational politics and disregard its negative connotation rather than appreciate its uniqueness in terms of individuality. Literature suggests that the perception of organizational politics depends upon the context of organization and individuals' own experience about politics. ${ }^{[26]}$ Some professionals consider organizational politics as an opportunity and a resource whereas; while some consider it as a threat. ${ }^{[26]}$ Therefore, it can be said that professionals who understand power and politics are the ones most likely to obtain resources needed to accomplish desired goals.

While sharing the perceptions about the value belief system, which nurse leaders possess, study participants stressed upon spirituality and morality in the workplace. Participants have claimed that these moral values provide valuable benefits for nurses and for the health care organization in terms of increased productivity, motivation, creativity, increased job satisfaction and organizational or job commitment. This would also develop ethical and spiritual leadership, which literature stresses about that nurses should develop spiritual leadership to address the challenges and the emerging demands of the organization. ${ }^{[27]}$ Several nursing authors have explained the positive relationship between spiritual leadership and job satisfaction. ${ }^{[28,29]}$

Furthermore, research studies also depict that spiritual leaders exhibit several qualities which support organizational goals along with job satisfaction by the stakeholders. Spiritual leaders tend to promote the sense of community, togetherness and respect even in a culturally diverse atmosphere. These leaders are concerned about their stakeholders' needs and issues and therefore the employees working under such leaders remain satisfied and become more contend and dedicated toward their work. ${ }^{[30,31]}$ Nurses in our context require such kind of understanding and professional support to be able to excel in their career and fulfillment of their required expectations from the profession.

The current study also talks about the traits of nursing leaders and managers which positively influence nurses' empowerment. The notion of traits of nursing leaders is viewed uniquely in literature, as compared to male, female managers exceed in their traits of transformational leadership qualities like teamwork, decision-making ability, collaboration, patience, commitment, devotion, etc. Literature also argues that women must be at the top leadership roles in a health care organization in order to lead the organization successfully. ${ }^{[32,33]}$ Finally, despite the non-constructive factors and challenges faced by nursing leaders, this study also shows that, nurses are striving towards achieving empowerment through constant struggle, and using constructive drives such as strong value belief system and improved quality of nursing education.

Nursing is predominately a female profession; therefore, all the nursing leaders interviewed were female. However, future studies could include male nursing leaders as well, in order to explore perception about empowerment to have a good mix gender in the study.

This study has identified many concepts related to the empowerment of nursing leaders from a Pakistani perspective. The findings of the study on empowerment could be used in practice as well as in education settings in order to strengthen the nurse's role and profession as well.

With regards to nursing education, few elective courses like politics, gender, and empowerment could be included in the nursing curriculum, especially in the Masters' program, and nursing leaders should be involved in the planning and implementation of such courses.

Since nurses' oppression is one of the greatest impeding factors for empowerment, awareness sessions can be arranged for the nurses in Pakistan, which can serve as a key step towards the understanding of being oppressed, its impact, and the strategies to overcome this oppression.

Once nurses enter in their practice, their leadership skills should be enhanced through mentorship program within the organization, to enable a smooth transition towards the road of leadership and to provide nurses with a guideline to function effectively according to the organizational norms and values. In addition, leadership exposures shall be provided to nurses within and outside the organization, in order to harness their potentials and inculcate leadership qualities in them, by which they can become transformed leaders, and work collaboratively in the health care system within and outside Pakistan. A strong networking system of nurses working in the public and private sectors should be developed to enable them to collectively strive for their common rights and goals, and achieve the desirable outcomes.

Most importantly, nursing regulatory bodies like Pakistan Nursing Council (PNC) and Pakistan Nursing Federation (PNF), play a pivotal role towards nurses' empowerment, and therefore these bodies should be strengthened by inducting strong nursing leadership.

The findings in this study will help nursing leaders to reflect on the notion of empowerment. Furthermore, nursing leaders can foster empowering the atmosphere in practice settings 
by applying the discovered concept from the frameworks of empowerment in a Pakistani context. Further research in this arena will hopefully add to the body of nursing knowledge.

\section{Conclusions}

Empowerment is a significant component in enhancing the image of the nursing profession in Pakistan in a constructive and pragmatic manner. The study identified various personal and professional factors affecting nurse's empowerment including political pressure, physician-centered organizational structures, and lack of advance educational competencies of nurses. Nevertheless, Nursing leaders in Pakistan continue to struggle to overcome the challenges and uphold the status and empowerment of nurses along with the nursing profession in the country.

The conceptual categories discovered in this study will help nursing leaders to reflect on their process of empowerment. As research has discovered, basic concepts of empowerment with different dimensions may help modify the nursing curriculum such as adding the courses of professional development, and leadership management. And thus, facilitate nursing educators to teach nurses by focusing on of all the dimension of empowerment. Furthermore, nursing leaders can foster the empowering atmosphere in practice settings by applying the discovered concept from the frameworks of empowerment from the perspective of Pakistan.

\section{ACKNOWLEDGEMENTS}

We would like to acknowledge Aga Khan University for providing seed money grant for this study.

\section{CONFLicts OF InTEREST Disclosure}

The authors declare they have no conflicts of interest.

\section{REFERENCES}

[1] Somers MJ, Finch L, Birnbaum D. Marketing nursing as a profession: integrated marketing strategies to address the nursing shortage. Health Marketing Quarterly. 2010; 27(3): 291-306. PMid: 20706896. http://dx.doi.org/10.1080/07359683.2010.495306

[2] Walter E. (Ed.). Cambridge Advanced Learner's Dictionary. Ernst Klett Sprachen. 2008.

[3] Jennings L, Na M, Cherewick M, et al. Women's empowerment and male involvement in antenatal care: analyses of Demographic and Health Surveys (DHS) in selected African countries. BMC Pregnancy \& Childbirth. 2014; 14(1): 1-11. PMid: 25174359 http://dx.doi.org/10.1186/1471-2393-14-297

[4] Lee-Rife SM. Women's empowerment and reproductive experiences over the Life-course. Social Science \& Medicine. 2010; 71(3): 634 642. PMid: 20621752. http://dx.doi.org/10.1016/j.socsc imed.2010.04.019

[5] Afifi M. Women's empowerment and the intention to continue the practice of female genital cutting in Egypt. Archives of Iranian Medicine. 2009; 12(2). PMid: 19249886.

[6] Manzoor QA. Impact of employees motivation on organizational effectiveness. Business management and strategy. 2012; 3(1): 1.

[7] Pool S, Pool B. A management development model: Measuring organizational commitment and its impact on job satisfaction among executives in a learning organization. Journal of Management Development. 2007; 26(4): 353-369. http://dx . doi .org/10.1108/0 2621710710740101

[8] Schaurhofer M, Peschl MF. Autonomy: starting point and goal of personal and social change: A constructivist perspective on knowledge management in empowerment processes. Kybernetes. 2005; 34(1-2): 261-277. http://dx.doi.org/10.1108/03684920510575834

[9] Christens BD, Winn LT, Duke AM. Empowerment and Critical Consciousness:A Conceptual Cross-Fertilization. Adolescent Research Review. 2015; 1-13.

[10] Gulzar S, Karmaliani R, Vertejee S, et al. A Qualitative Study of Nursing Leader's Perceptions of Professional Empowerment amongst Pakistani Nurses. International Journal of Nursing Education. 2015; 7(3). http://dx.doi.org/10.5958/0974-9357.2015.00174.9
[11] Schultheiss K. Imperial Nursing: cross-cultural challenges for women in the health professions: a historical perspective. Policy, Politics, \& Nursing Practice. 2010; 11(2): 151-157. PMid: 20679326. http://dx.doi.org/10.1177/1527154410377356

[12] Fletcher K. Image: changing how women nurses think about themselves. Literature review. Journal of Advanced Nursing. 2007; 58(3): 207-215. PMid: 17474909. http://dx.doi.org/10.1111/j.1 365-2648.2007.04285.x

[13] Takase M, Maude P, Manias E. Impact of the perceived public image of nursing on nurses' work behaviour. Journal of Advanced Nursing. 2006; 53(3): 333-343. PMid: 16441539. http://dx.doi.org/10. 1111/j.1365-2648.2006.03729.x

[14] Hemani H. History of nursing in Pakistan: a struggle for professional recognition. M.S.thesis. University of Alberta, Alberta, Canada. 2003.

[15] Freire P. Pedagogy of the oppressed. Bloomsbury Publishing; 1970.

[16] Hage AM, Lorensen M. A philosophical analysis of the concept empowerment; the fundament of an education-programme to the frail elderly. Nursing Philosophy. 2005; 6(4): 235-246. PMid: 16135215. http://dx.doi.org/10.1111/j.1466-769X.2005.00231.x

[17] Hagbaghery MA, Salsali M, Ahmadi F. A qualitative study of Iranian nurses' understanding and experiences of professional power. Human Resources for Health. 2004; 2(1): 9. PMid: 15217516. http://dx.doi.org/10.1186/1478-4491-2-9

[18] Graneheim UH, Lundman B. Qualitative content analysis in nursing research: concepts, procedures and measures to achieve trustworthiness. Nurse education today. 2004; 24(2): 105-112. PMid: 14769454. http://dx.doi.org/10.1016/j.nedt.2003.10.001

[19] Wall K. The Nurse-Physician Relationship. AJN The American Journal of Nursing. 2009; 109(10): 13. PMid: 21753454. http: //dx.doi.org/10.1097/01.NAJ.0000361465.56289.fc

[20] Hayes LJ, O'Brien-Pallas L, Duffield C, et al. Nurse turnover: A literature review - An update. International Journal of Nursing Studies. 2012; 49(7): 887-905. PMid: 22019402. http://dx.doi.org/10. 1016/j.ijnurstu.2011.10.001

[21] Fulton Y. Nurses' views on empowerment: a critical social theory perspective. Journal of Advance Nursing. 1997; 
26(3): 529-536. http://dx.doi.org/10.1046/j.1365-2648. 1997.t01-13-00999.x

[22] Speedy S, Jackson D. Power, politics and gender: issues for nurse leaders and managers. Nursing Leadership. 2016.

[23] Manojlovich M. Power and empowerment in nursing: Looking backward to inform the future. Online Journal of Issues in Nursing. 2007; 12(1). PMid: 17330984.

[24] Des Jardin KE. Political involvement in nursing — politics, ethics, and strategic action. AORN journal. 2001; 74(5): 613-622. http: //dx.doi.org/10.1016/S0001-2092 (06)61760-2

[25] Ellis JR, Hartley CL. Nursing in Today's World: Challenges, Issues, and Trends. ( $7^{t h}$ ed.). Philadelphia: Lippincott Williams \& Wilkins; 2001.

[26] Landells EM, Albrecht SL. The Positives and Negatives of Organizational Politics: A Qualitative Study. Journal of Business and Psychology. 2015; 1-18. http://dx.doi.org/10.1007/s1086 9-015-9434-5

[27] Crumpton $\mathrm{AD}$. An exploration of spirituality within leadership studies literature. 2011. Available from: http://www.inter-disciplinary.net/wp-content/u ploads/2011/02/Crumpton-paper.pdf
[28] Gupta M, Kumar V, Singh M. Creating satisfied employees through workplace spirituality: A study of the private insurance sector in Punjab (India). Journal of business ethics. 2014; 122(1): 79-88. http://dx.doi.org/10.1007/s10551-013-1756-5

[29] Indartono S, Wulandari SZ. Moderation effect of gender on workplace spirituality and commitment relationship: case of Indonesian ethics. Asian Journal of Business Ethics. 2014; 3(1): 65-81. http://dx.doi.org/10.1007/s13520-013-0032-1

[30] Park SM, Word J. Driven to service: Intrinsic and extrinsic motivation for publicand nonprofit managers. Public Personnel Management. 2012; 41(4): 705-734. http://dx.doi.org/10.1177/0091026 01204100407

[31] Fairholm GW. Real Leadership: How Spiritual Values Give Leadership Meaning: How Spiritual Values Give Leadership Meaning. ABC-CLIO. 2011. PMid: 22205558.

[32] Zenger J, Folkman J. Are women better leaders than men. Harvard Business Review. 2012; 15: 80-8.

[33] Chamiec-Case R, Sherr M. Exploring how social work administrators integrate spirituality in the workplace. Social Work and Christianity. 2006; 33(3): 268-287. 